Integration of Simulation and Experiment in Particle Transport, Deposition and Removal

Dr. Goodarz Ahmadi, Clarkson University

Dr, Ahmadi is a Distinguished Professor and Dean of Engineering at Clarkson University. 


\title{
Integration of Simulation and Experiment in Particle Transport, Deposition and Removal
}

\author{
Goodarz Ahmadi \\ Department of Mechanical and Aeronautical Engineering \\ Clarkson University, Potsdam, NY, 13699-5725, USA
}

Particle transport, deposition and removal occur in many important processes in microelectronic, imaging and pharmaceutical industries. In addition, numerous environmental processes involve particle transport, deposition and removal. In the last three decades, significant research progress in the areas of particle transport, deposition and removal has been made. A series of courses were developed to make the new important research findings available to seniors and first year graduate students in engineering departments through specialized curricula. This project also involved an integration of numerical simulations and experiments in a series of courses. These courses are composed of four modules:

- Fundamentals of particle transport, dispersion, deposition, and removal.

- Computational modeling of particle transport, deposition, and removal.

- Experimental study of particle transport, deposition, and removal, and aerosol instrumentation.

- Industrial applications of particle transport, deposition, and removal.

The materials for the course sequence were made available on the web and the courses were taught six times each and were taught twice at two campuses simultaneously. More recently, the first course is also offered simultaneously on-line using lecture capture facilities. The purpose of this presentation is to provide information about the effectiveness of using web-based modules for enhanced learning of in-class material and inform the audience about the availability of the course material for use at other institutions. Assessment of student learning through their projects and course grades was also presented and discussed.

\section{INTRODUCTION}

Understanding particle transport, deposition and removal is of crucial importance to many technologies that are critical for the competitiveness of the US microelectronic, imaging and pharmaceutical industries. In addition, solving a number of environmental problems requires a detail understanding of particle transport processes. In the last decade, significant research progress in the areas of particle transport, deposition and removal has been made. The primary objective of this combined research and curriculum development project is to make the fruits of these new important research findings 
available to seniors and first year graduate students in engineering through the development and offering of a sequence of specialized courses. In these courses, the process of particle transport, deposition and removal and re-entrainment are described. An extensive website for the course materials was developed and the courses were taught in-class at Clarkson University and simultaneously available via the web and video conferencing for students in Syracuse University. In 2012 the first course is also offered on-line simultaneously.

\section{PARTICLE TRANSPORT COURSE MODULES}

These combined research and curriculum development (CRCD) courses are composed of four modules. The models are:

- Fundamental of particle transport, dispersion, deposition and removal.

- Computational modeling of particle transport, deposition and removal.

- Experimental study of particle transport, deposition and removal.

- Industrial applications of particle transport, deposition and removal.

The front page of the course web is shown in Figure 1. The lecture notes and the calculations models are uploaded into the course web and are available in both pdf form as well as html form.

\section{Module I: Fundamental concepts:}

In Module I, the descriptions of fundamental theory of aerosols including hydrodynamic forces (drag, lift), and adhesion forces are described. The nature of particle adhesion and removal are also discussed. This module also contains the description of particle interaction with laminar flow, Brownian motion process, and particle deposition by diffusion, interception and impaction.

The interaction of particles with turbulence and turbulent deposition, normally taught as part of a second course, as also presented in this section. Details of computational modeling of turbulent flows are presented, and classical models of turbulent deposition are described. The process of aerosol charging and transport under the action of electrical forces and turbulence are also presented. The topics in Module I, thus provides a complete knowledge of fundamental particle forces that the students will use in later modules.

We have added a number of computational modules to make the course presentations of the materials more interactive. These calculation modules help the student develop a better understanding of physical meaning of the complex concepts.

\section{Module II: Computer Simulations}

We refined and developed several computer modules that were incorporated into the course sequence. One class of examples concerned with exploring the flow and particle transport in a variety of obstructed ducts. JAVA based simulation programs were developed and these programs were incorporated in the modules dealing with the motion of aerosol particles in the obstructed duct flows. The students will be able to interactively 
use the programs to explore the effects of various forces (gravity, drag, lift, Brownian), materials properties (particle density), and the flow geometry on the motion and deposition of particles. A module was developed for illustrating Brownian particle motion in cross flows. The flow field in this module is a parabolic velocity profile between two parallel plates. The particle equation of motion includes Brownian motion, drag, lift, and gravity. Figure 2 shows the user interface for this module. Here, particles are injected from a nozzle in the middle of the channel and the Brownian dispersion of particles can be visualized. The module can also be used to illustrate the effects of the lift force on larger particles. Student can select values of the particle diameter and density, the number of particles, and the centerline fluid velocity and understand the relative magnitudes of the different forces.

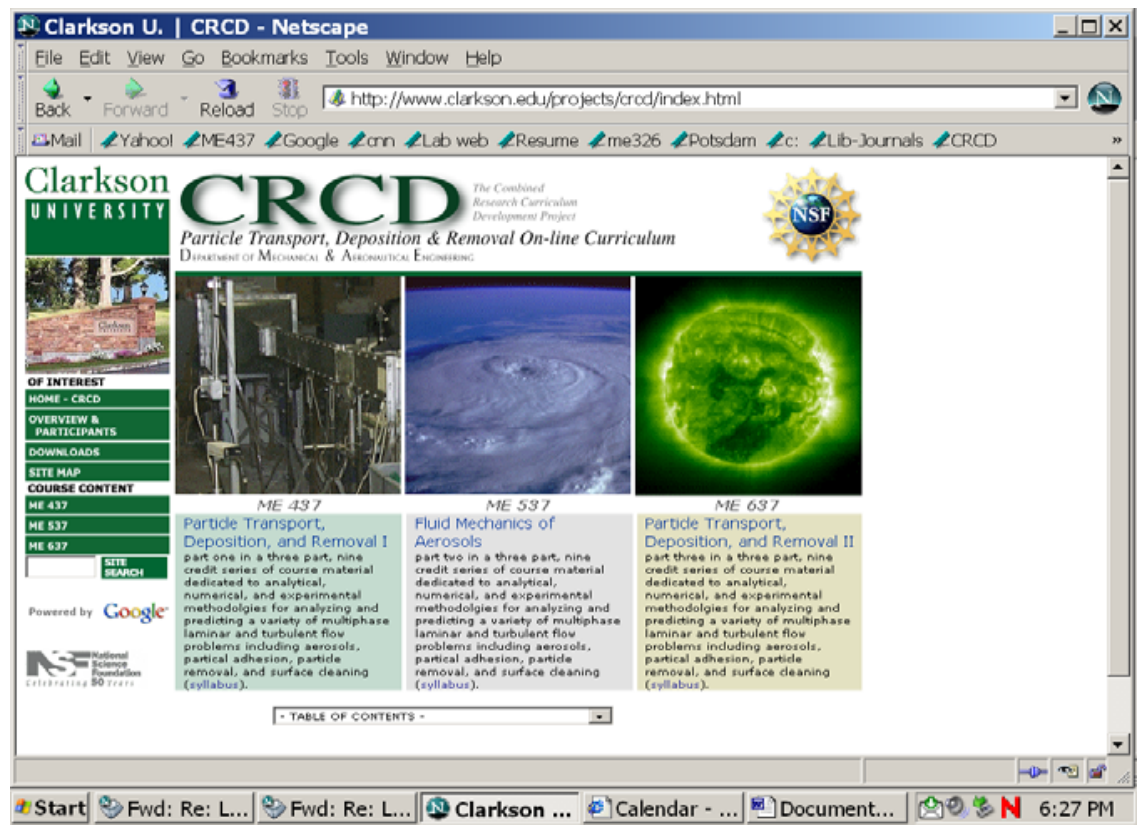

Figure 1. Front webpage of CRCD and the related courses.

\section{Module III: Experimental}

The course sequence includes several experimental modules. One main experiment is the measurement in the aerosol wind tunnel with the use of Particle Image Velocimeter (PIV). The aerosol wind tunnel is located in the Turbulence and Multiphase Flow Laboratory at Clarkson University. The laser used was a $120 \mathrm{~mJ} \mathrm{Nd}$ :YaG laser with a $20^{\circ}$ adjustable width sheet generator. In this experiment, the sheet width was 0.5 $\mathrm{mm}$. The digital camera that was used was a Kodak ES1.0 MegaPlus camera. The camera had a pixel range of $1008 \times 1008$. The pixel size was 25 micrometers and the interframe delay between pictures was 12 microseconds. A picture of the experimental setup is show in Figure 3. A sample PIV measurement of the velocity field behind a step is shown in Figure 4. 


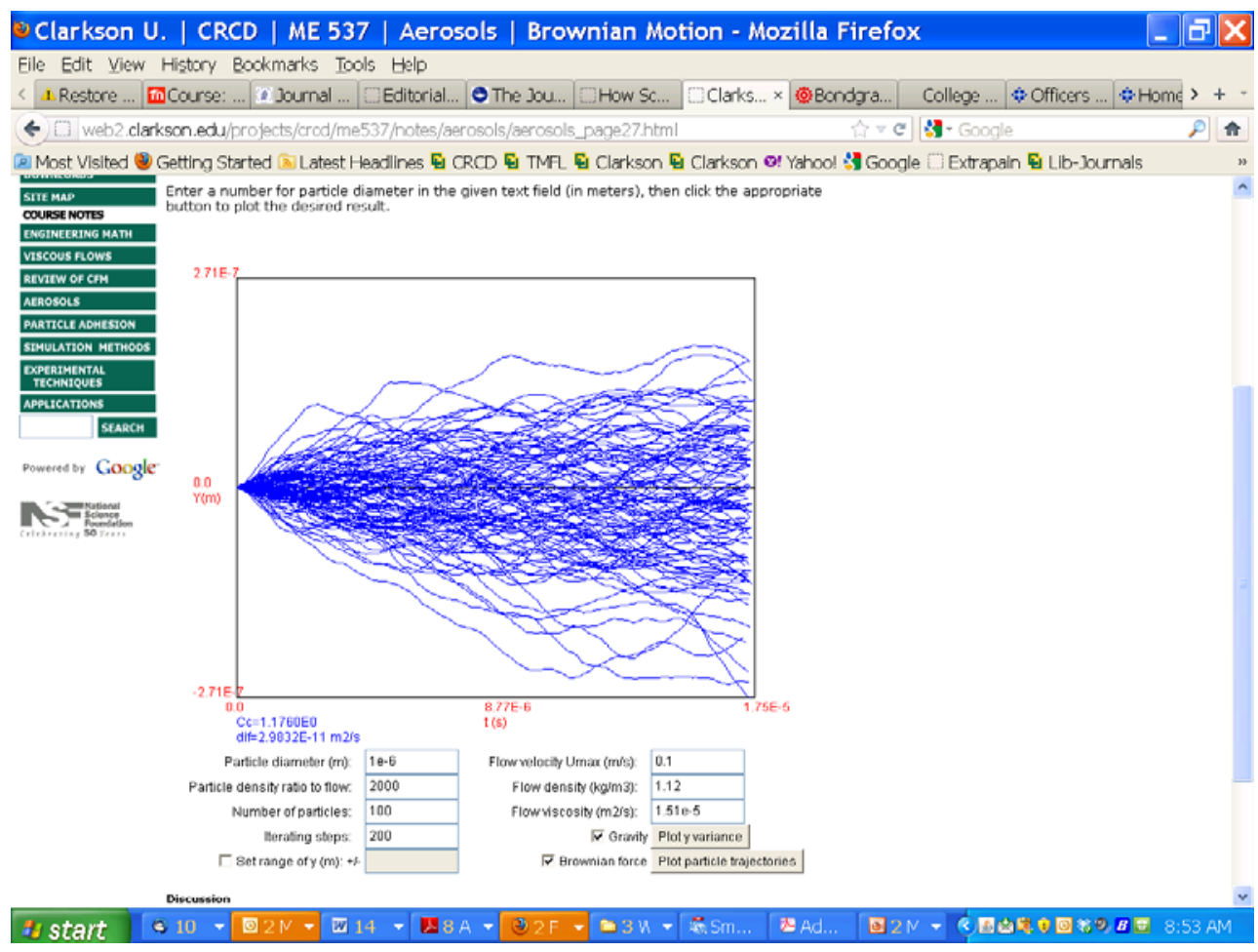

Figure 2. User interface for the module for Brownian particle motions in cross flows.

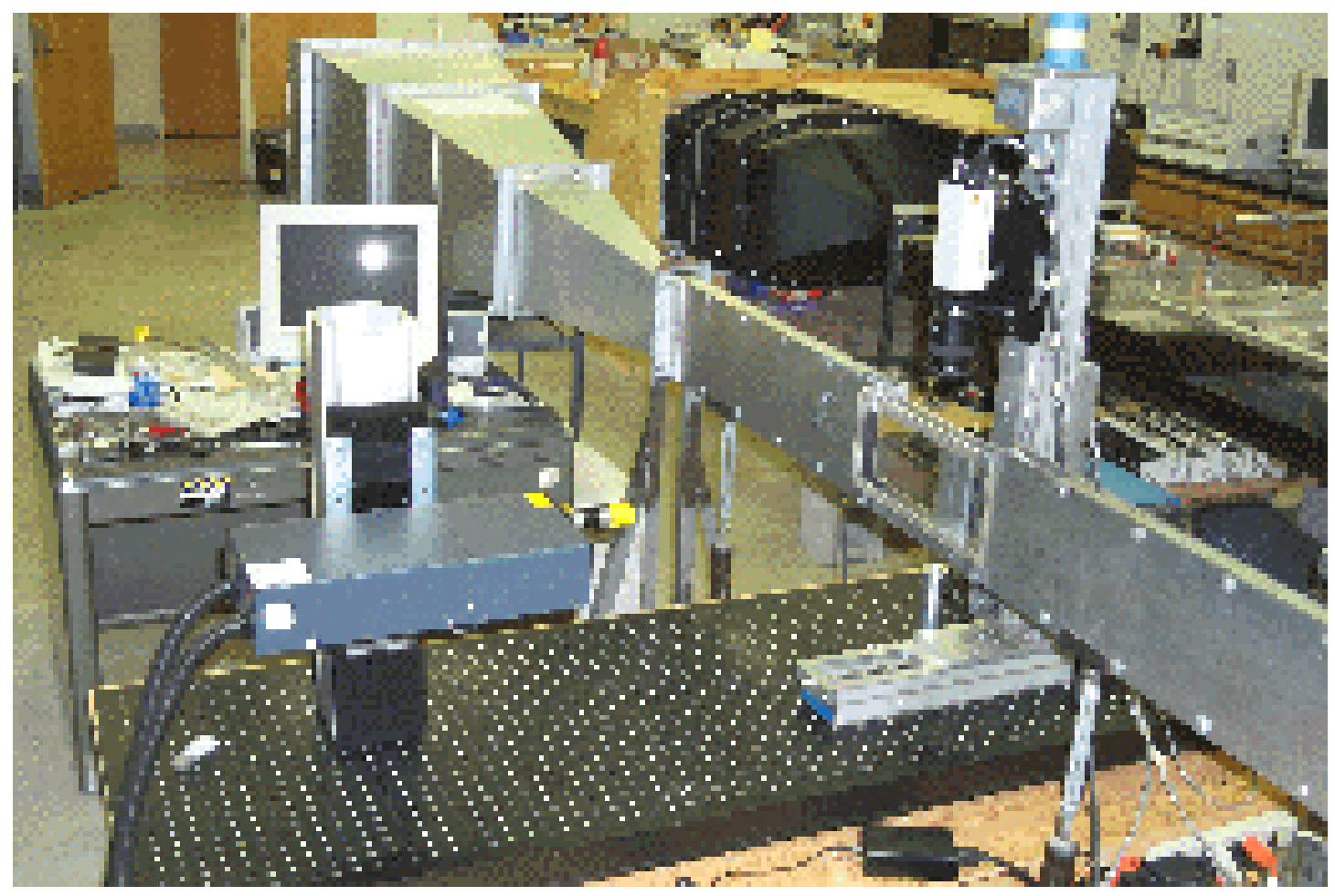

Figure 3. A picture of the aerosol wind tunnel. 


\section{Module IV: Applications}

The applications module includes a number of examples from air pollution to xerography. For example, students can extend the material learned in Modules 1-3 to solve complex air pollution problems (e.g., particle pollution near Peace Bridge area in the south west Buffalo, NY because of traffic emissions, Figures 5 and 6).

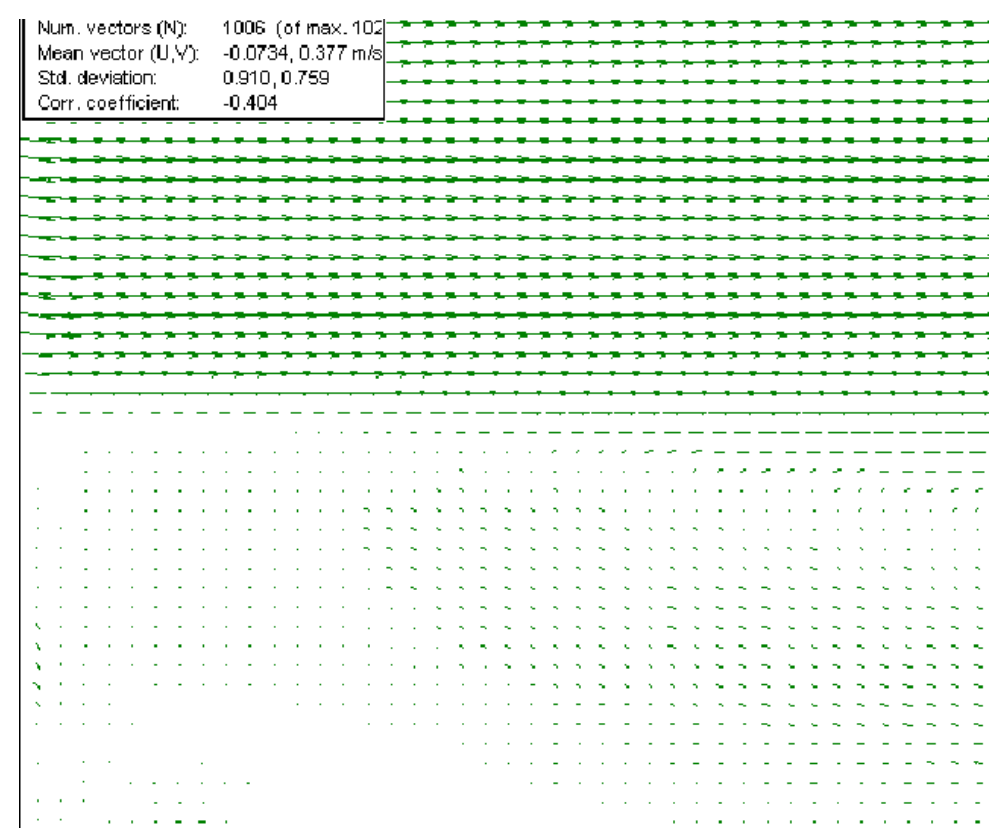

Figure 4. Sample PIV measurement behind a step in the aerosol wind tunnel.

\section{EXPERIMENTAL COURSE}

A separate experimental aerosol mechanics and instrumentation course was developed by Dr. Suresh Dhaniyala at the Department of Mechanical and Aeronautical Engineering at Clarkson University. The course includes both lecture-based instruction on the theory related to aerosol measurements and laboratory experiments for a hands-on experience. During the lectures, a wide-range of aerosol topics, as related to aerosol measurements and instrumentation, were covered, including: a review of fundamental aerosol mechanics, particle statistics, size distributions, aerosol electrical properties, and aerosol sampling. The lectures helped provide students with a theoretical understanding of the basics of popular aerosol measurement techniques, such as electrical mobility instruments, inertial samplers, mass measurement devices, and diffusion-based instruments.

The experimental aspect of the course included four extended experiments where a wide range of aerosol instruments and analysis techniques popular in aerosol science were used. 


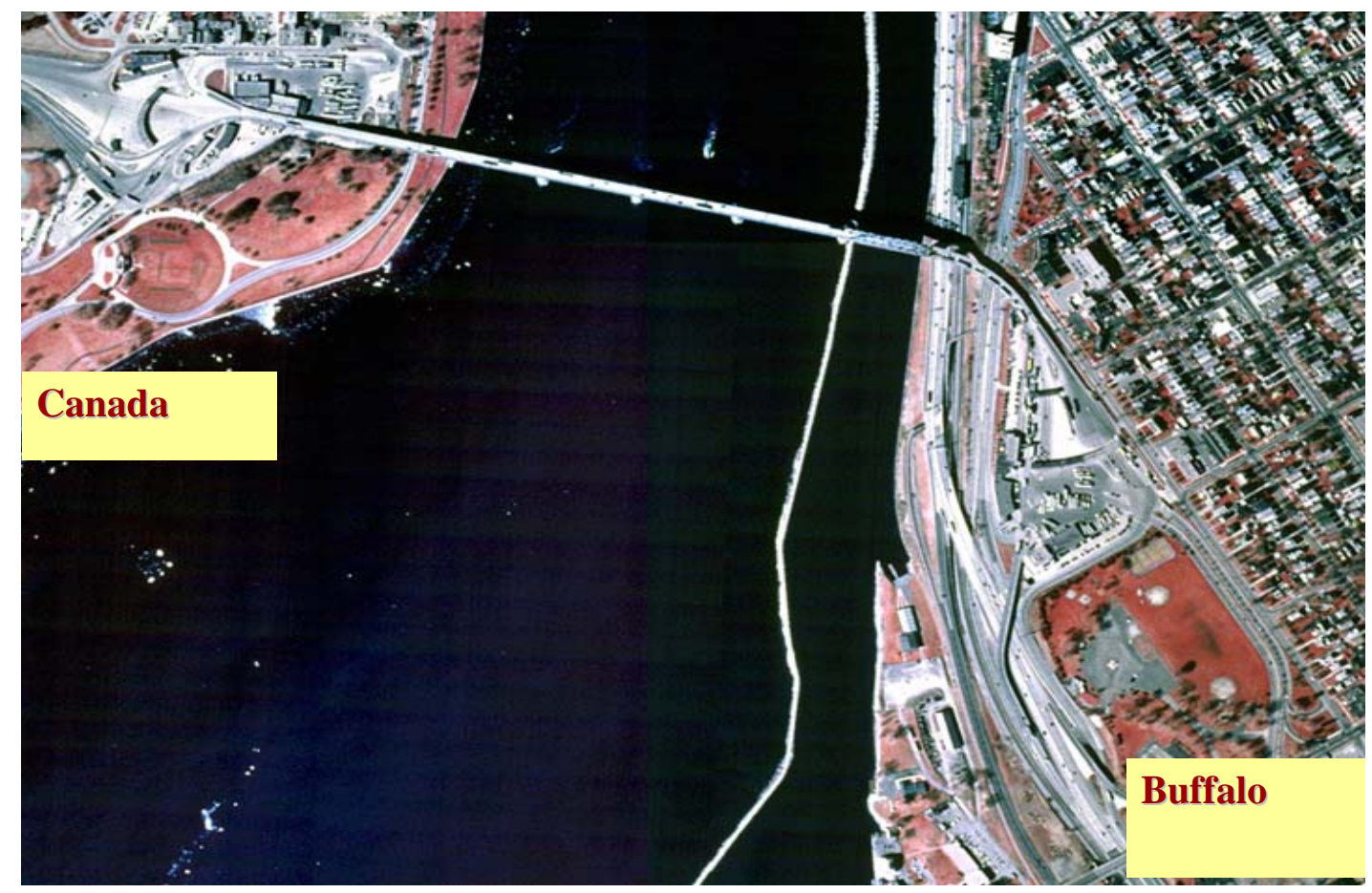

Figure 5. A picture of Peace Bridge area and city of Buffalo.

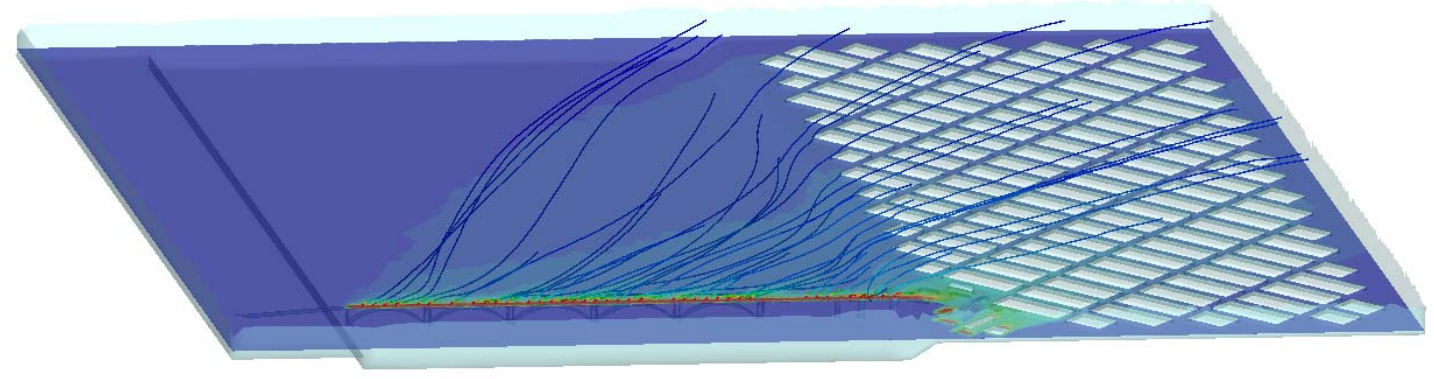

Figure 6. Sample computational results for pollutant dispersion from Peace Bridge traffic.

\section{COURSE WEB EFFECTIVENESS:}

The effectiveness of the course website was assessed in two ways:

1. Usability tests were conducted on an early version of the site and conducted again on the revised version of the site. In both tests, participants were given tasks to find course material and use the calculation model available on the site. The purpose of these tests was to determine how efficiently the participants could complete each task. 
2. A survey questionnaire was administered to students enrolled in the courses designed to assess the students' satisfaction with the website.

\section{USABILITY TESTS}

The Usability Testing Lab in the Eastman Kodak Center for Excellence in Communication at Clarkson University was set up to record users testing out the website. Participating in the first test on the early version of the website were twelve student volunteers: six Mechanical Engineering majors and six Information Technology majors. Information from these tests was communicated to the website designers. A year later after the website had been redesigned a second usability test was conducted with two Mechanical Engineering majors and three Information Technology majors

For both test sessions a list of twelve tasks was devised that would cover a variety of possible uses of the website. All tasks required the students to search the site for courserelated information. One task asked the students to do a calculation using the calculation model currently embedded into the site.

The results indicate that the participants using the revised site completed the tasks more efficiently.

\section{Original Site}

Average number of clicks, searches, scrolls to complete each task per user: $\mathbf{3 . 7 0}$

$\underline{\text { Revised Site }}$

Average number of clicks, searches, scrolls to complete each task per user: 2.56

\section{Original Site}

Average number of failed or incomplete completions of the task per user: $\mathbf{1 . 4 1}$

$\underline{\text { Revised Site }}$

Average number of failed or incomplete completions of the task per user: $\mathbf{0 . 6 0}$

\section{Survey Questionnaire}

Twenty-two students filled out a questionnaire upon completing the course, using the website to assist their learning. Overall, these students found the website useful for their needs: The specific results of the survey are:

\section{The website was used to access information and employ calculation models:}

- $77 \%$ used the website to read the course syllabus

- $86 \%$ used the website to read homework assignments

- $77 \%$ used the website to download course notes

- $54 \%$ used one or more of the calculation models

\section{Students found the availability of course notes to be useful:}

- $86 \%$ found the course notes to be easy to moderately easy to find.

- $96 \%$ found the course notes helpful to moderately helpful to their coursework. 
- $86 \%$ found the course notes to be easy to moderately easy to understand.

\section{Students found the calculation models to be useful:}

- $81 \%$ found the calculation models to be helpful to moderately helpful.

- $81 \%$ found the calculation models to be easy to moderately easy to use.

\section{Overall, $86 \%$ found the website to be very to moderately helpful to their coursework.}

\section{STUDENT LEARNING ASSESSMENT}

Course grade and student projects were used for assessing the student learning by the development of the new web based materials. The student course final exam grades and course projects for five years before the new web-based course development were compared with the recent five years after the availability of the web based courses. It was found the average final exam grades improved from 81.5 to 86.7, which showed about $6 \%$ increase. The averaged course project grades also showed a $4.7 \%$ increase. In addition, the student comments on their course evaluation were generally positive.

\section{CONCLUSIONS}

The development of a sequence of web-based courses on particle transport, deposition and removal was described. Different modules of the course are outlined and the integration of simulations and experiments into the curriculum are described. The student learning and the suitability of the course website in helping the student learning were assessed. The results showed that the availability of the course material and computational modules on the website were very helpful to student learning, and students at multiple campuses could take the course simultaneously. The student evaluations of the experimental course suggested that the hands-on component was very well received by the students. The associated experience of technical writing for the lab reports was also noted as being very valuable by the students.

\section{References:}

http://web2.clarkson.edu/projects/crcd/ 